\title{
Autoantibodies frequency in children with visceral leishmaniosis
}

\author{
Luciana B Paim-Marques $^{1,2^{*}}$, Raquel Lisboa ${ }^{1}$, Eugenio Pacceli ${ }^{1}$ \\ From 21st European Pediatric Rheumatology (PReS) Congress \\ Belgrade, Serbia. 17-21 September 2014
}

\section{Introduction}

The visceral leishmaniosis (VL), or Calazar, is a chronic severe systemic disease, potentially fatal to humans. Currently, VL is the prototype of a specific immune dysfunction resulting from parasitism of leishmania donovani in macrophages, producing a broad spectrum of clinical and immunological reversible only with specific treatment. Serum Analysis from infected adult patients demonstrated the presence of autoantibodies against cellular and humoral components, and circulating immune complexes.

\section{Objectives}

To identify the profile of autoantibodies in pediatric patients with VL and its correlation with clinical outcome.

\section{Methods}

Through a transversal study, was investigated the occurence of autoantibodies ( antinuclear antibodies (ANA), anti-DNA , anti-SM , anti-RNP , anti-SSb , anti-SSa, lupus anticoagulant, IgG and IgM anticardiolipin (aCL) antibodies) in 34 patients (under 18 years) with diagnosis of $\mathrm{VL}$, at the beginning and shortly after treatment, in the period October 2010 to March 2011.

\section{Results}

The incidence of autoantibodies present at the beginning in patients with VL was $64,7 \%$ (10 with ANA positive $(29,4 \%), 7$ with lupus anticoagulant antibodies positive (20,58\%), 8 with IgM aCL antibodies positive (23,5\%) and 5 with IgG aCL antibodie positive $(14,7 \%)$ and 1 with Anti-RNP (2,9\%). Sex, age, visceromegaly, nutritional status, treatment, use of corticosteroids, infections, hemophagocytic syndrome, febrile neutropenia, hemoglobin level and platelet count parameters were correlated with the presence of antibodies (table:1). It was found associated anaemia $(\mathrm{p}<0,05)$ with the antibody presence, but more studies are needed to evaluate the presence of hemolytic anemia associated. Infections: sepsis, pneumonia and urinary tract infection in $71,42 \%$ of total patients, but not correlated with antibodies. Autoimmunity was greatly reduced after treatment; the statistical significance remained after stratification in ANA.

\section{Conclusion}

Visceral leishmaniasis appears to correlate positively with the presence of ANA, lupus anticoagulant, IgG ang IgM $\mathrm{aCL}$, in children, as in adults possibly by triggering a systemic humoral response of Th2. We found association statistically significant with lower hemoglobin level in these patients. Further studies are needed to evaluate the antibodies pattern in these infections.

\section{Disclosure of interest}

None declared.

\section{Authors' details}

'Pediatria, Hospital Dr Waldemar de Alcântara, Brazil. ²Pediatric rheumathology, Fortaleza University, Fortaleza, Brazil.

Published: 17 September 2014

doi:10.1186/1546-0096-12-S1-P101

Cite this article as: Paim-Marques et al:: Autoantibodies frequency in children with visceral leishmaniosis. Pediatric Rheumatology 2014 12(Suppl 1):P101.

${ }^{1}$ Pediatria, Hospital Dr Waldemar de Alcântara, Brazil

Full list of author information is available at the end of the article 